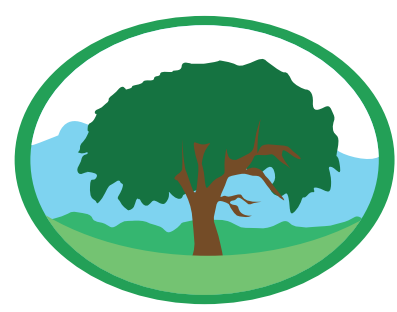

\title{
Índices de fragilidade ambiental parciais da bacia do Rio Iraizinho
}

Silva, L. F. ${ }^{1}$; Mlenek, D. C. ${ }^{2}$; Leandro, D. ${ }^{3}$; Quadro, M.S. ${ }^{4}$; Rocha, F. C. ${ }^{5}$; Nadaleti, W.C. ${ }^{6}$; Castro, A.S. ${ }^{7}$

${ }^{1}$ Acadêmico do Curso de Cartográfica e de Agrimensura - Departamento de Geomática - Universidade Federal do Paraná, UFPR/Curitiba - PR, luis.silvađufpr.br

${ }^{2}$ Acadêmico do Curso de Cartográfica e de Agrimensura - Departamento de Geomática - Universidade Federal do Paraná, UFPR/Curitiba - PR, dyeison.mlenekahotmail.com

${ }^{3}$ Professora Adjunta - Centro de Engenharias - Universidade Federal de Pelotas, UFPel/Pelotas - RS, diuliana.leandrolagmail. com

${ }^{4}$ Professor Adjunto - Centro de Engenharias - Universidade Federal de Pelotas, UFPel/Pelotas - RS, mausqahotmail.com

${ }^{5}$ Acadêmico do Curso de Engenharia Geológica - Centro de Engenharias - Universidade Federal de Pelotas, UFPel/Pelotas RS, felipecr_15layahoo.com.br

${ }^{6}$ Professor Adjunto - Centro de Engenharias - Universidade Federal de Pelotas, UFPel/Pelotas - RS, willian.nadaletidufpel. edu.br

${ }^{7}$ Professora Adjunta - Centro de Engenharias - Universidade Federal de Pelotas, UFPel/Pelotas - RS, andreascastrolagmail. com

Palavras-chave: modelagem espacial, gestão, planejamento.

\section{Resumo}

A bacia do Rio Iraizinho, localizada na Região Metropolitana de Curitiba, no decorrer da última década, passou por um processo de desenvolvimento urbano e aumento populacional intenso, tendo como consequência, mudanças ambientais bruscas. Nessa região os conflitos ambientais são visíveis, especialmente devido ao surgimento de áreas de riscos face à intensificação da industrialização sobre as áreas de mananciais. Desta forma, esta bacia, vem se tornando cada vez mais frágil e suscetível aos processos de degradação. Neste trabalho se desenvolveu a geração de mapas de índice de fragilidade ambiental parciais utilizando a metodologia de Índice de Fragilidade Ambiental, na qual utilizou conhecimentos das Ciências Geodésicas e áreas afins, visando gerar mapas para o cálculo de fragilidade ambiental para subsídio a políticas de planejamento e gestão para a bacia do Rio Iraizinho. Mapeou-se os temas: ação antrópica, áreas de preservação permanente), clima, cobertura vegetal, declividade, rochas e solo.

\section{Environmental fragility partial index Iraizinho River basin}

Key words: modeling spatial, management, environmental planning

\begin{abstract}
The Iraizinho river basin, located in the metropolitan region of Curitiba, during the last decade, went through a process of urban development and high population growth, as a consequence, abrupt environmental changes. In this region the environmental conflicts are more visible, especially due to the emergence of risk areas face the intensification of industrialization on the watershed areas. Thus, this basin is becoming increasingly fragile and susceptible to the degradation. This paper developed the generation of environmental vulnerability index maps using the environmental fragility index methodology, which used knowledge of Geodetic Sciences and related fields in order to generate maps for the environmental fragility calculation for subsidy planning policies and management for the Iraizinho river basin. Is mapped the following topics: human action, permanent preservation areas, climate, vegetation cover, slope, rocks and soil.
\end{abstract}




\section{INTRODUÇÃO}

O desenvolvimento tecnológico, cientifico e econômico da sociedade, contribui com o avanço da exploração dos recursos naturais. Em função deste fator torna-se cada vez mais urgente a realização de um planejamento físico territorial, não somente com enfoque socioeconômico, mas, também ambiental, levando-se em consideração não apenas as potencialidades, mas principalmente a fragilidade das áreas com intervençóes derivadas de açóes humanas.

A susceptibilidade do sistema de sofrer intervençôes, ou de ser alterado está ligada a fragilidade ambiental da área. O mapeamento da fragilidade ambiental, segundo Costa et al. (2009), permite avaliar as potencialidades do meio ambiente de forma integrada, compatibilizando suas características naturais com suas restriçôes. Neste contexto, Spörl; Ross (2004) e Messias (2012), afirmam que, as modificaçóes nos diferentes componentes da natureza, como por exemplo, qualquer alteração no relevo, solo, vegetação, clima e recursos hídricos, acarretam o comprometimento da funcionalidade do sistema, quebrando o seu estado de equilíbrio dinâmico. Deste modo, a exploração de recursos naturais, a supressão de cobertura vegetal para a implantação de culturas ou pastagem, a ocupação desordenada, as diferentes formas de poluição, entre outros, levam ao estado de desequilíbrio ambiental. Assim a análise de índices de fragilidade ambiental fornece informaçôes que podem auxiliar em tomadas de decisôes para a utilização da área estudada para empreendimentos futuros de forma que determinado investimento não seja realizado em local de alto índice de fragilidade podendo vir a trazer prejuízos e degradação ao ambiente.

De acordo com Ross (1990) o planejamento não pode ser formulado a partir de uma leitura estática do ambiente, mas inserida no processo de ocupação que norteia o desenvolvimento e a apropriação do território e de seus recursos.

A presente pesquisa tem por finalidade a análise da região da bacia do Rio Iraizinho através da obtenção de dados geográficos, informaçôes de imagens de satélites, fotografias aéreas, informaçôes geológicas e hidrográficas, dados geodésicos gerados por posicionamento GNSS (Sistema de Navegação Global por Satélite) e outras informaçóes relevantes para geração de mapas para subsidio para a avaliação de riscos ambientais. Estes dados foram correlacionados através da geração de mapas temáticos com a utilização de um Sistema de Informaçôes Geográficas - SIG, no qual gerou-se mapas de declividade do terreno, cobertura vegetal, uso do solo, tipo de solo, litologia, clima, ocupação humana e existência ou náo de áreas de preservação permanente, aplicados em um modelo de determinação de Índices de fragilidade ambiental parciais definidos na metodologia IFA, desenvolvida por Leandro (2013). Os mapas gerados com os índices parciais de fragilidade ambiental permitiram uma visão do ambiente como um todo, destacando as áreas problemáticas, delimitando áreas potencialmente mais frágeis que necessitam de maior atenção dentro da bacia hidrográfica.

\section{MATERIAL E MÉTODOS}

\section{1 Área de Estudo}

A bacia hidrográfica do Rio Iraizinho (Figura 1) está localizada no Primeiro Planalto Paranaense, mais precisamente na Regiáo Metropolitana de Curitiba, no Município de Piraquara, com coordenadas geográficas $-25^{\circ} 24^{\prime} 40^{\prime \prime}$ de latitude Sul e $-49^{\circ} 00^{\prime} 10^{\prime \prime}$ de longitude Oeste, apresentando $52,01 \mathrm{~km}^{2}$ sendo que um de seus rios é utilizado para abastecimento público de Curitiba e Regiáo Metropolitana. Altitude na regiáo varia entre 881,03 a 1105,19 m, e é formada por solos do tipo: Cambissolo Háplico na região leste, Gleissolo Háplico na região oeste e Latossolo Vermelho-Amarelo na área central da bacia. Quanto a litologia a bacia é composta por rochas metamórficas e sedimentares, sendo que no extremo leste a formação é basicamente Gnaisses, e a oeste é composta por sedimentos areno-silticoargilosos depositados em ambiente fluvial, intercalados com camadas de areia fina a grossa e cascalhos. 


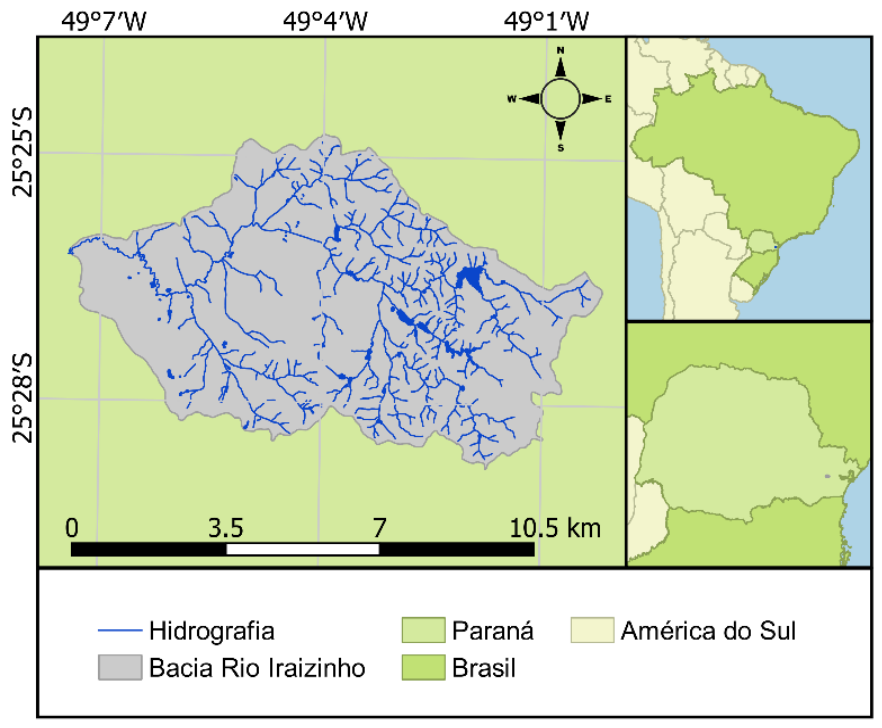

Figura 1 - Mapa de Localização da Bacia Hidrográfica do Rio Iraizinho - PR

\subsection{Determinação de índices de fragilidade parciais}

O conceito de fragilidade ambiental está "aliado à qualidade dos espaços físicos, normalmente como 'fragilidade do meio físico', está ligada também às causas dos desequilíbrios, que podem ter origens diversas, mas que frequentemente se relacionam com a antropização do meio (SANTOS; VITTE, 1998).

Ross (1994) propóe uma análise empírica da fragilidade dos ambientes naturais e antropizados, onde deve-se fazer o levantamento dos elementos do meio físico como: solos, geologia, vegetação e relevo, avaliando-os de forma integrada com o uso e ocupação do solo. Baseando-se em Tricart (1977), que trabalha nas Unidades Ecodinâmicas e na concepçáo de que o ambiente é analisado sob a ótica da Teoria dos Sistemas e na existência de ambientes em equilíbrio dinâmico (estáveis) e ambientes em desequilíbrio (instáveis), Ross, estabelece duas unidades:

- Unidades Ecodinâmicas Estáveis são aquelas que se encontram em equilíbrio dinâmico e não sofreram intervenção humana;

- Unidades Ecodinâmicas Instáveis ou de instabilidade emergente são aquelas intensamente modificadas pela ação antrópica.

Vários autores têm adotado essa metodologia e gerado informaçôes significativas para políticas de planejamento e gestão ambiental Pachechenik (2004), Donha et al., (2006), Spörl (2007), e Oliveira et al.
(2008). Da mesma forma a metodologia IFA também é baseada em índices de classificação semelhante à de Ross (1994), na qual se estabeleceu níveis diferenciados para caracterizar cada aspecto considerado na seguinte graduação: 1.Muito Baixa; 2.Baixa; 3.Média; 4.Alta; 5.Muito Alta. Nas seçôes 2.2.1 à 2.2.6 são descritos os índices parciais adotados na metodologia aplicada.

\subsubsection{Declividade do Terreno (Relevo)}

Segundo Santos (2004), a inclinação do terreno em relação à horizontal condiciona e repercute em fatores como: formas de relevo, erosão, potencialidades para uso agrícola, restriçóes para ocupação urbana, manejos e práticas conservacionistas. Partindo da proposta de Ross (1994), adotou os níveis de fragilidade relacionando-os aos intervalos de declividade conforme é mostrado na Tabela 1.

Tabela 1 - Classe de Fragilidade da Declividade.

\begin{tabular}{ll} 
CLASSES DE FRAGILIDADE & INTERVALOS DE DECLIVIDADE \\
\hline 1-Muito Baixa & até $6 \%$ \\
2-Baixa & de 6 a $12 \%$ \\
3-Média & de 12 a $20 \%$ \\
4-Alta & de 20 a $30 \%$ \\
5-Muito Alta & acima de $30 \%$ \\
\hline
\end{tabular}

\subsubsection{Solo}

Em relação ao estudo do solo, Ross (1994) mostra que os solos em função de suas características morfológicas, apresentam diferentes níveis de fragilidade e que associados com o relevo, clima, litologia, elementos da pedogênese e fatores que determinam suas características físicas e químicas, dentro deste contexto, estabeleceu-se classes de fragilidade para os solos ou erodibilidade dos mesmos, levando em conta o escoamento superficial e a concentração das águas pluviais, Tabela 2.

Tabela 2 - Fragilidade dos tipos de Solos.

\begin{tabular}{ll}
$\begin{array}{l}\text { GRAUS DE } \\
\text { FRAGILIDADE }\end{array}$ & TIPOS DE SOLOS \\
\hline Muito Baixa & $\begin{array}{l}\text { Latossolo Roxo, Latossolo Vermelho Escuro } \\
\text { e Vermelho Amarelo textura argilosa }\end{array}$ \\
Baixa & $\begin{array}{l}\text { Latossolo Amarelo e Vermelho Amarelo } \\
\text { textura média/argilosa }\end{array}$ \\
Média & $\begin{array}{l}\text { Latossolo Vermelho Amarelo, Terra Roxa, } \\
\text { Terra Bruna, Podzólico Vermelho-Amarelo } \\
\text { textura média/argilosa }\end{array}$
\end{tabular}




\begin{tabular}{ll} 
Alta & $\begin{array}{l}\text { Podzólico Vermelho-Amarelo textura } \\
\text { média/arenosa, Cambissolos }\end{array}$ \\
Muito Alta & $\begin{array}{l}\text { Podzolizados com cascalho, Litólicos e } \\
\text { Areias Quartzosas }\end{array}$ \\
\hline & Fonte: Ross, 1994.
\end{tabular}

\subsubsection{Cobertura Vegetal e Uso do Solo}

Uso e ocupação da terra é um tema básico para planejamento ambiental, porque retrata as atividades humanas que podem significar pressão e impacto sobre os elementos naturais (SANTOS, 2004). Com base na análise da proteção dos solos pela cobertura vegetal, resultante dos trabalhos de gabinete e de campo (ROSS, 1996), organizou os graus de proteção do solo pela cobertura vegetal (Tabela 3) tanto natural como cultivada em ordem decrescente conforme a capacidade de proteção.

\subsubsection{Rochas}

Outro fator determinante da potencialidade de erosão de uma determinada área está relacionado à sua litologia, ou seja, quanto ao tipo de rocha de que é constituída, quais as suas características físicas (composição mineral, distribuição e tamanho dos grãos, cor, textura, estrutura e grau de compactação dos

Tabela 4 - Litologia Associada ao Grau de Fragilidade.

\begin{tabular}{|c|c|c|c|}
\hline $\begin{array}{l}\text { TIPOS DE } \\
\text { ROCHAS }\end{array}$ & LITOLOGIAS & $\begin{array}{l}\text { GRAU DE } \\
\text { VULNERABILIDADE }\end{array}$ & $\begin{array}{l}\text { ÍNDICE DE } \\
\text { FRAGILIDADE } \\
\text { AMBIENTAL }\end{array}$ \\
\hline Metamórficas & Quartizitos ou metaquartizitos & 1,0 & Muito Baixa \\
\hline Ígneas & Riolito, Granito, Dacito & 1,1 & \\
\hline $\begin{array}{l}\text { Ígneas } \\
\text { Intrusivas }\end{array}$ & Granodiorito, Granulitos & 1,2 & \\
\hline Metamórficas & Migmatitos, Gnaisses & 1,3 & \\
\hline $\begin{array}{l}\text { Ígneas } \\
\text { Intrusivas }\end{array}$ & Fonólito, Nefelina Sienito, Traquito, Sienito & 1,4 & Baixa \\
\hline Ígneas & Andesito, Diorito, Basalto & 1,5 & \\
\hline $\begin{array}{l}\text { Ígneas } \\
\text { Intrusivas }\end{array}$ & Anortosito, Gabro, Peridotito & 1,6 & \\
\hline Metamórficas & Milonitos, Quartzo muscovita, Biotita-xisto, Clorita xisto & 1,7 & \\
\hline $\begin{array}{l}\text { Ígneas e } \\
\text { Metamórficas }\end{array}$ & Piroxenito, Anfibolito Kimberlito, Dunito & 1,8 & Média \\
\hline Ígneas & Homblenda, Tremolita, Actinolita xisto & 1,9 & \\
\hline Metamórficas & Estaurolita xisto, xistos granatíferos & 2,0 & \\
\hline Metamórficas & Filito, Metassiltito & 2,1 & \\
\hline Metamórficas & Ardósia, Metargilito & 2,2 & \\
\hline Metamórficas & Mármores & 2,3 & Alta \\
\hline Sedimentares & Arenitos quartzosos ou Ortoquartizitos & 2,4 & \\
\hline Sedimentares & Conglomerados, Subgrauvacas & 2,5 & \\
\hline Sedimentares & Grauvacas, Arcózios & 2,6 & \\
\hline
\end{tabular}

Tabela 3 - Graus de Proteção por tipos de Cobertura Vegetal.

\begin{tabular}{|c|c|}
\hline $\begin{array}{l}\text { GRAUS DE } \\
\text { PROTEC̦ÃO }\end{array}$ & TIPOS DE COBERTURA VEGETAL \\
\hline Muito Alta & $\begin{array}{l}\text { Florestas/Matas Naturais, Florestas } \\
\text { cultivadas com biodiversidade }\end{array}$ \\
\hline Alta & $\begin{array}{l}\text { Formações arbustivas naturais com } \\
\text { Estrató herbáceo denso. Formacões } \\
\text { arbustivas densas (mata secundária, cerrado } \\
\text { denso, capoeira densa). Mata homogênea } \\
\text { de Pinus densa. Pastagens cultivadas sem } \\
\text { pisoteio de gado. Cultivos de ciclo longo } \\
\text { como o cacau. }\end{array}$ \\
\hline Média & $\begin{array}{l}\text { Cultivo de ciclo longo em curvas de nível, } \\
\text { terraceamento com café, laranja com } \\
\text { forrageiras entre as ruas. Pastagem com } \\
\text { baixo pisoteio. Silvicultura de eucaliptos com } \\
\text { sub-bosque de nativas }\end{array}$ \\
\hline Baixa & $\begin{array}{l}\text { Culturas de ciclo longo de baixa densidade } \\
\text { (café, pimenta-do-reino, laranja), com solo } \\
\text { exposto entre ruas, culturas de ciclo curto } \\
\text { larroz, trigo, feijão, soja, milho, algodão) com } \\
\text { cultivo em curvas de nível/ terraceamento }\end{array}$ \\
\hline $\begin{array}{l}\text { Muito Baixa } \\
\text { a Nula }\end{array}$ & $\begin{array}{l}\text { Áreas desmatadas e queimadas } \\
\text { recentemente, solo exposto por arado/ } \\
\text { gradeação, solo exposto por caminhos, } \\
\text { estradás, terraplanagens, culturas de ciclo } \\
\text { curto sem práticas conservacionistas. }\end{array}$ \\
\hline
\end{tabular}

sedimentos ou rochas). Nesta pesquisa se utilizou uma escala de grau de fragilidade desenvolvida por Crepani et al. (2001) para as litologias mais comumente encontradas, relacionando-as a sua resistência ao intemperismo, como pode ser observado na Tabela 4 . 


\begin{tabular}{|c|c|c|c|}
\hline Sedimentares & Siltitos, Argilitos & 2,7 & Muito Alta \\
\hline Sedimentares & Folhelhos & 2,8 & \\
\hline Sedimentares & Calcários, Dolomitos, Margas, Evaporitos & 2,9 & \\
\hline Sedimentares & Sedimentos Inconsolidados: Aluviões, Colúvios etc. & 3,0 & \\
\hline
\end{tabular}

Fonte: Adaptado de Sporl, 2007

\subsubsection{Ação Antrópica}

Para o critério de ocupação humana utilizou-se na modelagem as características da Tabela 5, para qualificar as áreas de acordo com o índice de fragilidade ambiental de média a alta em função da poluição do ar, água, solo e geração e detritos devido à ação antrópica.

Tabela 5 - Classificação do Índice de fragilidade ambiental em função da Ação antrópica.

\begin{tabular}{|c|c|c|}
\hline AC̣ÃO ANTRÓPICA & FRAGILIDADE & VALOR \\
\hline Estradas, sem ocupação & Muito Baixa & 1 \\
\hline $\begin{array}{l}\text { Edificações sem aglomerado, } \\
\text { humanó, loteamento, armazém, } \\
\text { silo }\end{array}$ & Baixa & 2 \\
\hline $\begin{array}{l}\text { Indústrias, aglomerados humano } \\
\text { lárea urbana baixa e médial) } \\
\text { com tratamento de detritos }\end{array}$ & Média & 3 \\
\hline $\begin{array}{l}\text { Indústrias e aglomerados } \\
\text { humanos lárea urbana alta) com } \\
\text { tratamento de detritos } \\
\text { aglomerados humano lárea } \\
\text { urbana baixa, } \\
\text { média e altal) com tratamento de } \\
\text { detritos parcial (vila), áreas de } \\
\text { mineraçáo, areais e granja }\end{array}$ & Alta & 4 \\
\hline $\begin{array}{l}\text { Indústrias e aglomerados } \\
\text { urbanos sem tratamento de } \\
\text { detritos }\end{array}$ & Muito Alta & 5 \\
\hline
\end{tabular}

\subsection{6 Áreas de Preservação Permanente}

A definição dos critérios para o desenvolvimento do sistema de diagnóstico de índices de fragilidade foi baseada nas normas legais relativas à Legislação Ambiental, pois a Política Nacional do Meio Ambiente é um instrumento essencial para o licenciamento ambiental de qualquer atividade.

A metodologia IFA baseou-se na Resolução $\mathrm{N}^{\circ}$. 303, de 20 de março de 2002, a qual define áreas de preservação permanente dentro do território nacional e outros espaços territoriais especialmente protegidos, sendo estes instrumentos de relevante interesse ambiental, os quais integram o desenvolvimento sustentável, objetivo das presentes e futuras gerações. Essa classifica o índice de fragilidade ambiental como alto (Tabela 6), para as áreas de Preservação Permanente e corpos de água em área urbana sejam naturais ou artificiais, pois segundo Leandro (2013), essas são áreas mais frágeis, na qual qualquer alteração nesses ambientes gerará perdas e danos a todo o ecossistema. Este autor também classifica como índice médio áreas que distam até $500 \mathrm{~m}$ das áreas classe alto, avalia que essas áreas possuem ligação direta com o ecossistema mais frágeis e consequentemente qualquer alteração nessa área influenciará nesses ecossistemas.

Tabela 6 - Classificação do Índice de fragilidade ambiental em função da Áreas de Preservação Permanente.

\begin{tabular}{ll} 
FRAGILIDADE & $\begin{array}{l}\text { EXISTÊNCIA DE ÁREAS DE PRESERVAÇÃO } \\
\text { PERMANENTE }\end{array}$ \\
\hline Alta & $\begin{array}{l}\text { Áreas de Preservação e corpos de água } \\
\text { em área urbana sejam naturais ou } \\
\text { artificiais, } 30 \mathrm{~m} \text { em seu entorno }\end{array}$ \\
Média & $\begin{array}{l}\text { Áreas que distam até } 500 \mathrm{~m} \text { de Áreas de } \\
\text { Preservação e de corpos de áqua em área } \\
\text { urbana séjam naturais ou artificiais }\end{array}$ \\
Baixa & Outras \\
\hline & Fonte: Leandro (2013)
\end{tabular}

\subsubsection{Clima}

O clima é uma generalização ou integração das condiçóes do tempo para um determinado período, em uma determinada área (SCHIAVETTI; CAMARGO, 2002).

Esse é classificado através elementos e fatores climáticos, o primeiro são grandezas que quantificam o clima (temperatura, pressão atmosférica, evaporação, entre outros). $\mathrm{O}$ segundo relaciona fatores que condicionam a regularidade do clima em determinada área, como, por exemplo: relevo do local, latitude, distância de corpos de água.

O intemperismo é controlado diretamente pelo clima através da precipitação pluviométrica e da temperatura (SPÖRL, 2007). E esse é um condicionante ecológico para fauna e flora, também para a evolução do relevo. O tipo climático de uma região é uma informação importante nas atividades de planejamento, já que condiciona toda a dinâmica do ambiente. Na Tabela 7 são apresentadas as características pluviométricas associadas ao índice de fragilidade ambiental. 
Tabela 7 - Características Pluviométricas.

\begin{tabular}{|c|c|}
\hline ÍNDICE DE FRAGILIDADE & CARACTERÍSTICAS PLUVIOMÉTRICAS \\
\hline Muito Baixo & $\begin{array}{l}\text { Situação pluviométrica com distribuição regular ao longo do ano, com volumes não muito } \\
\text { superiores a } 1000 \mathrm{~mm} / \mathrm{ano}\end{array}$ \\
\hline Baixo & $\begin{array}{l}\text { Situação pluviométrica com distribuição regular ao longo do ano, com volumes anuais não muito } \\
\text { superiores a } 2000 \mathrm{~mm} / \mathrm{ano}\end{array}$ \\
\hline Médio & $\begin{array}{l}\text { Situação pluviométrica com distribuição anual desigual, com períodos secos entre } 2 \text { e } 3 \text { meses de } \\
\text { inverńo, e no verão com maiores intensidades de dezembro a março }\end{array}$ \\
\hline Alto & $\begin{array}{l}\text { Situação pluviométrica com distribuiccão anual desigual, com períodos secos entre } 3 \text { e } 6 \text { meses, } \\
\text { e alta' concentração das chuvas no vérão entre novembro e abril quando ocorrem de } 70 \text { a } 80 \% \text { do } \\
\text { total de chuvas }\end{array}$ \\
\hline Muito Alto & $\begin{array}{l}\text { Situacão pluviométrica com distribuição regular, ou não, ao longo do ano, com grandes volumes } \\
\text { anuaís ultrapassando } 2500 \mathrm{~mm} / \mathrm{ano} \text { ou ainda, comportamentos pluviométricos irregulares ao } \\
\text { longo do ano, com episódios de chuvas de alta intensidade e volumes anuais baixos, geralmente } \\
\text { abaixo de } 900 \mathrm{~mm} / \text { ano (semiárido) }\end{array}$ \\
\hline
\end{tabular}
Fonte: Adaptado de Sporl, 2007

\subsection{Dados espaciais}

O primeiro procedimento utilizado para o desenvolvimento desta pesquisa foi a realização do levantamento bibliográfico e cartográfico o que resultou na produção de documentos cartográficos de todos os temas envolvidos, tais como dados altimétricos, (curvas de nível e pontos cotados), tipo de solo, cobertura vegetal e uso do solo, dados climatológicos, dados geológicos e dados hidrográficos sendo estes dados obtidos do Instituto das Águas do Paraná, da SUDERHSA (Superintendência de Desenvolvimento de Recursos Hídricos e Saneamento
Ambiental) e IBGE (Instituto Brasileiro de Geografia e Estatística).

Os dados do Instituto das Águas do Paraná e da SUDERHSA se encontravam no sistema de referência SAD-69 (sistema de referência topocêntrico, que está defasado tecnologicamente), e do IBGE, que se encontra em SIRGAS2000. Esses foram normatizados através da conversão para o Datum WGS-84, sistema de referência geocêntrico, o mesmo utilizado pelo sistema GPS (Sistema de Posicionamento Global). Para a produção dos mapas temáticos, utilizou-se as bases cartográficas em formato digital conforme a Tabela 8.

Tabela 8 - Escala e resolução espacial dos dados de origem

\begin{tabular}{|c|c|c|c|c|}
\hline DADOS & ESCALA & $\begin{array}{l}\text { PORCÃO, } \\
\text { DETECTÁVEL } \\
\text { NO TERRENO } \\
(\mathrm{m})\end{array}$ & $\begin{array}{l}\text { RESOLUCÃO } \\
\text { ESPACIAL (m) }\end{array}$ & FONTE \\
\hline $\begin{array}{l}\text { Dados Altimétricos (curvas de } \\
\text { nível e pontos cotados) }\end{array}$ & $1: 10.000$ & 10 & - & Instituto das Águas do Paraná/ SUDERHSA \\
\hline Tipo de solo & $1: 20.000$ & 20 & 10 & IBGE \\
\hline Cobertura vegetal e uso do solo & $1: 10.000$ & 10 & 5 & Instituto das Águas do Paraná/ SUDERHSA \\
\hline Dados Geológicos & $1: 20.000$ & 20 & 10 & IBGE \\
\hline Dados Hidrográficos & $1: 10.000$ & 10 & - & Instituto das Águas do Paraná \\
\hline
\end{tabular}

Para a produção dos mapas temáticos associados aos índices de fragilidade ambiental parciais utlizouse SIG comercial ArcGis 10.1, o qual possibilitou a manipulação e a interpretação dos dados gerados por meio das tabelas de atributos, entre as quais foram analisadas as seguintes classes de uso do solo: área urbana, floresta (floresta ombrófila densa, floresta ombrófila mista e mata ciliar), campo/agricultura, solo exposto e corpos d'água, declividade do terreno, solo, rochas, ação antrópica, áreas de preservação permanente e clima, as quais foram identificadas a partir da análise espacial a partir dos dados vetoriais e seus respectivos atributos.

\section{RESULTADOS E DISCUSSÃO}

A partir da análise espacial dos dados de origem, tornou-se possível a elaboração dos seguintes mapas temáticos: ação antrópica, APP's, clima, cobertura vegetal, declividade, rochas e solo, conforme a metodologia de Ross (1994) Crepani et al. (2001) e Leandro (2013) correlacionados a bacia apresentada na Figura 2. 
Figura 2 - Mapa de ocupação da Bacia Hidrográfica do Rio Iraizinho - PR

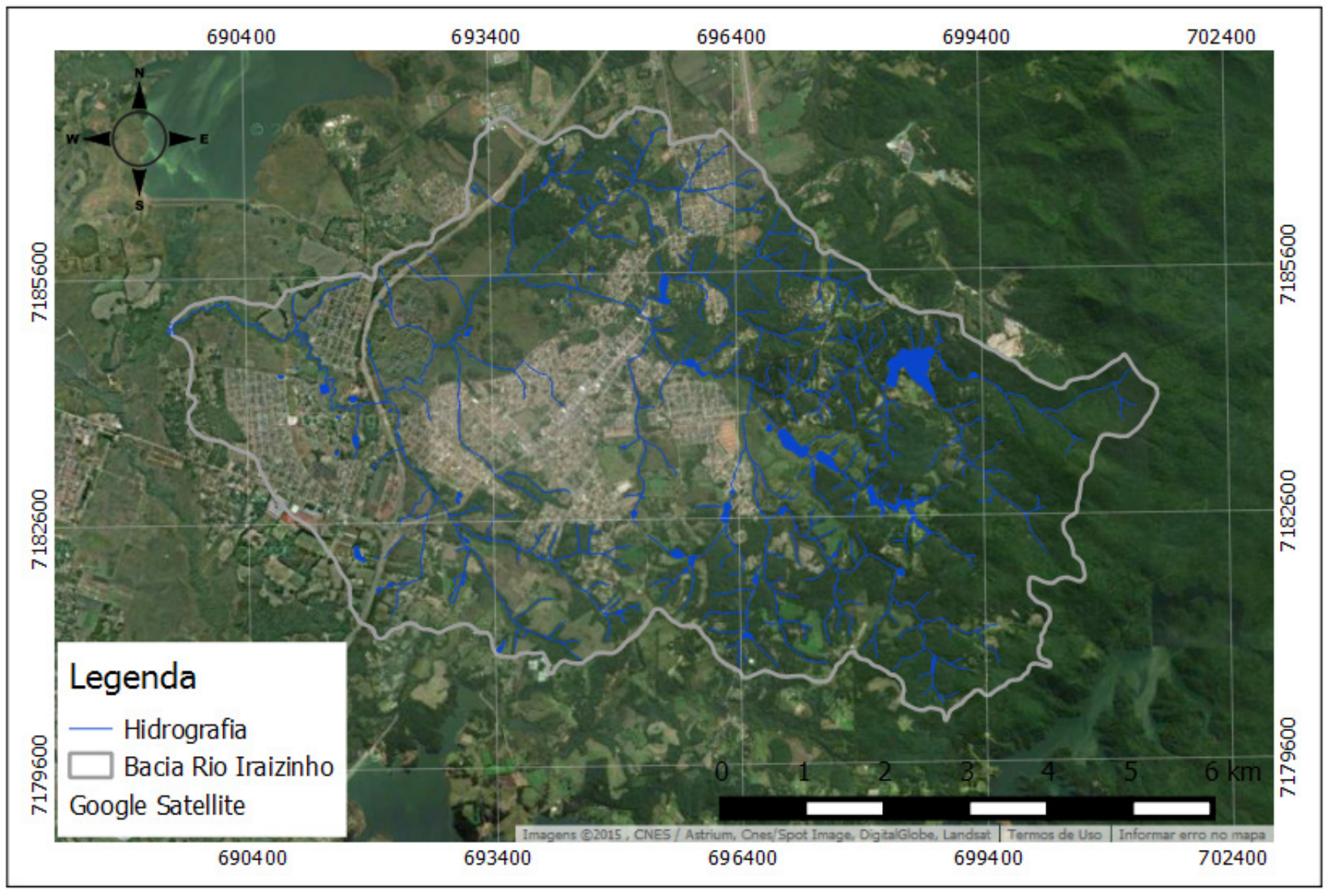

\subsection{Mapa da Declividade do Terreno}

De acordo com Spörl; Ross (2004), Spörl (2007), Leandro (2013) a declividade (relevo) é considerada a variável com maior peso, sendo um critério essencial para a determinação dos índices de fragilidade ambiental. Analisando as variações altimétricas na bacia do Rio Iraizinho observou-se que os valores de altitude variam de 878 a 1223 m. No mapa de fragilidade parcial de declividade da bacia (Figura 3) ressaltou-se que a área apresenta variaçóes bruscas de declividade na área leste da bacia, na regiâo próxima a Serra do Mar, a qual apresentou índices de fragilidade de declividade altos ou muito altos. A oeste da bacia são existem áreas mais planas e consequentemente menos frágeis. 
Figura 3 - Mapa de Índice Parcial de Fragilidade de Declividade da Bacia Hidrográfica do Rio Iraizinho - PR

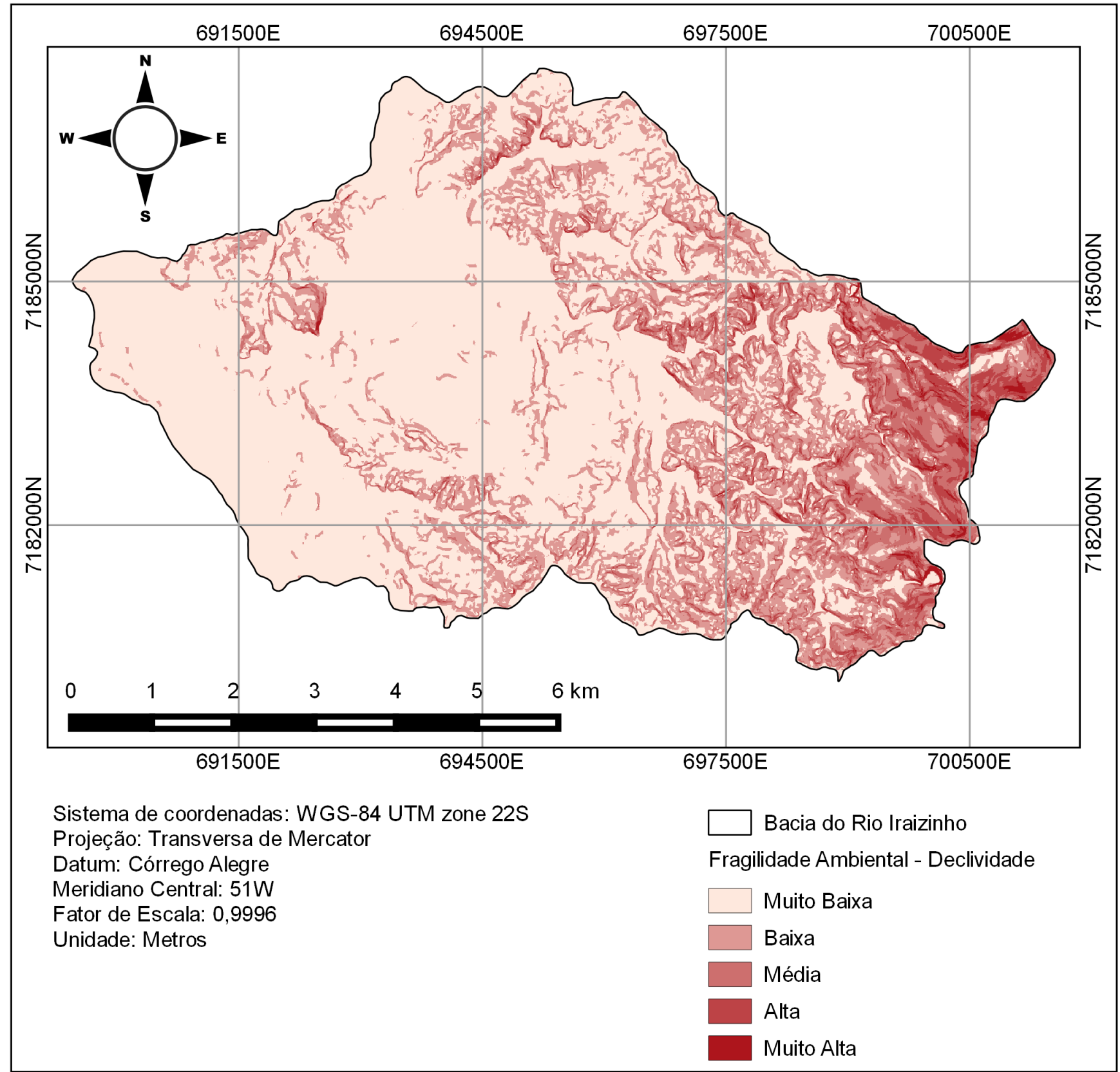

\subsection{Mapa do Índice parcial de Fragilidade do Solo}

A partir da definição das classes do mapa de fragilidade do solo, mapeou-se as áreas com índices de fragilidade mais baixos até os mais elevados. Sendo que a bacia apresenta um solo relativamente estável na maior parte das áreas, apresentando índices de maior fragilidade em maior concentração na parte leste e oeste da bacia, como pode-se observar na Figura 4. 
Fiaura 4 - Mana de Índice Parcial de Fravilidade do Solo da Bacia Hidroaráfica do Rio Iraizinho - PR

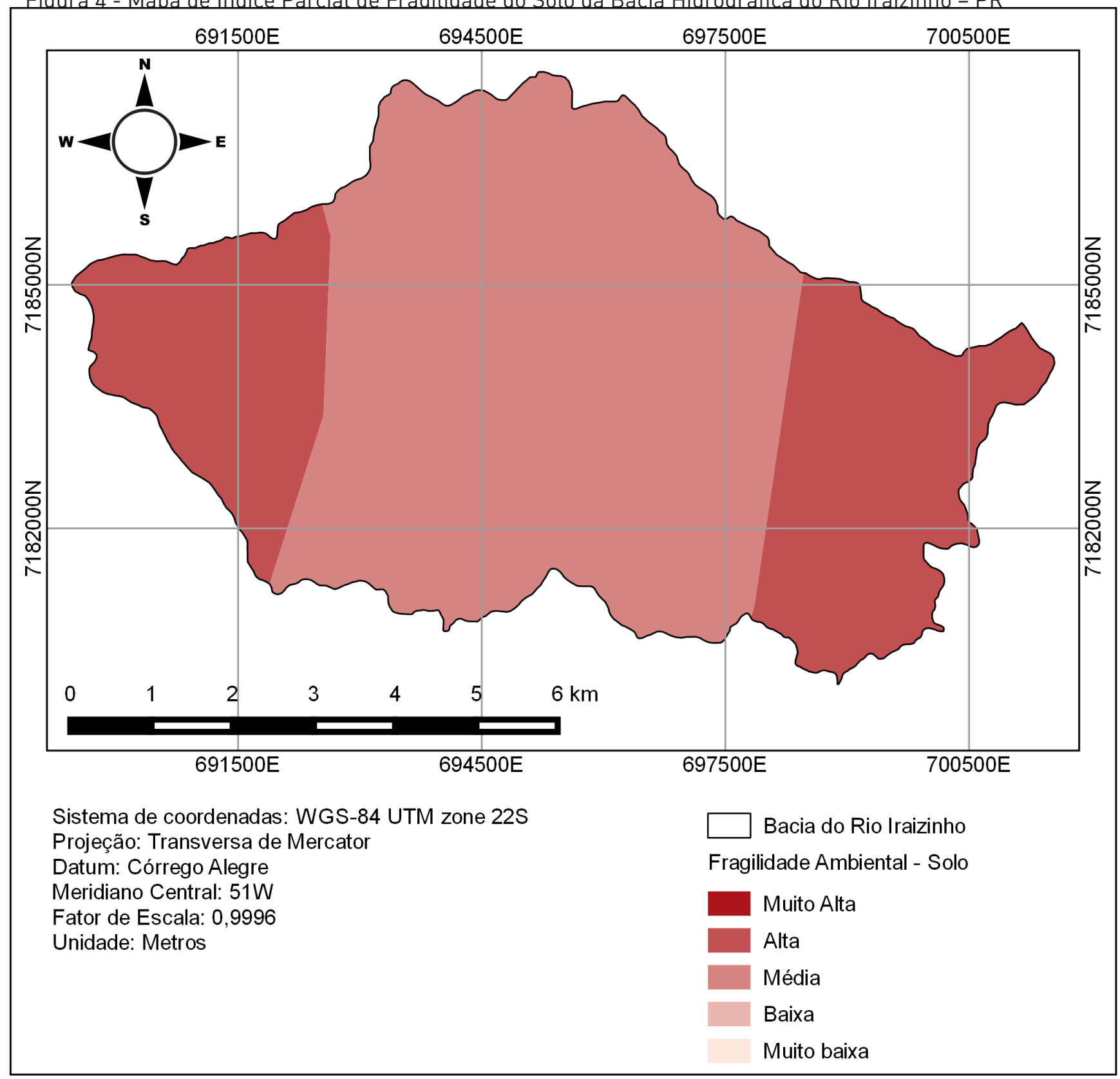

\subsection{Mapa do Índice parcial de Cobertura vegetal e Uso do solo}

Na Figura 5 apresenta-se o resultado da classificação dos índices de fragilidade ambiental para o tema cobertura vegetal e uso do solo. Essa bacia apresenta uma área consideravelmente preservada, apresentando índices de maior fragilidade em maior concentração na parte sul e alguns pequenos focos nas extremidades das regiốes norte e oeste da bacia. 
Figura 5 - Mapa de Índice Parcial de Fragilidade de Cobertura Vegetal da Bacia Hidrográfica do Rio Iraizinho - PR

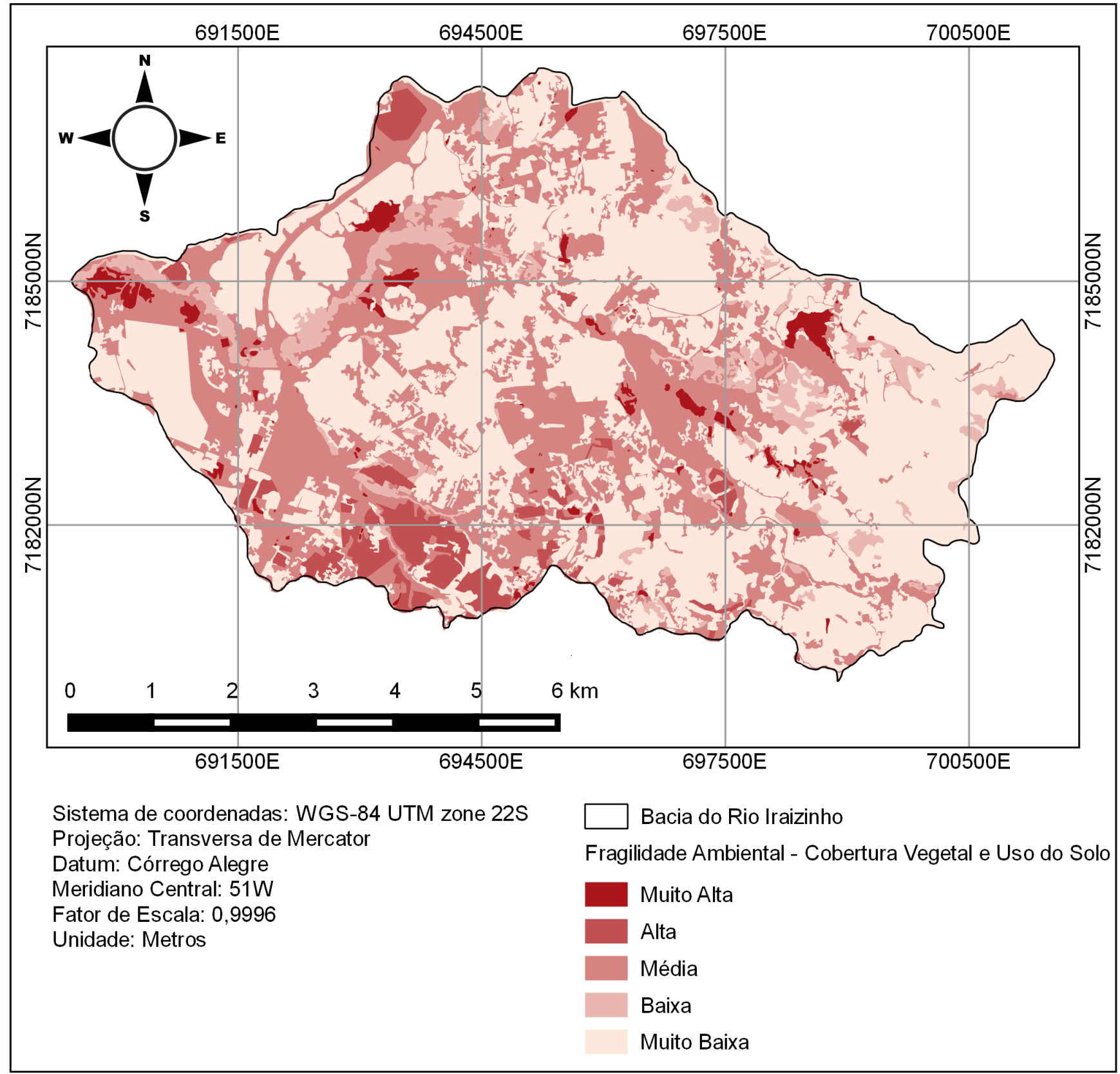

\section{4 Índice parcial de Fragilidade de Rochas}

A formação Guabirotuba é predominante em todo baixo curso da bacia, sendo depositada em um ambiente propício ao surgimento de extensos leques aluvionais, marcados por canais meandrantes de dimensões variadas, com circulação periódica de água, composta por sedimentos argilosos, intercalados com arenitos feldspáticos de granulação média a grossa, com seixos de quartzo, blocos e até matacóes confinados entre as camadas argilosas do período pleistocênico ou pliopleistocênico, depositados em discordância sobre o cristalino (CHUEH, 2004).

Com as informações básicas de litologia da bacia elaborou-se o mapa de fragilidade de rochas, no qual podemos constatar que foram encontrados somente duas classes de índices de fragilidade, sendo elas, muito baixa e muito alta. As áreas de maior fragilidade se encontram na região oeste da bacia gerando ramificações ao longo do sentido leste. 
Figura 6 - Mapa de Índice Parcial de Fragilidade de Rochas da Bacia Hidrográfica do Rio Iraizinho - PR

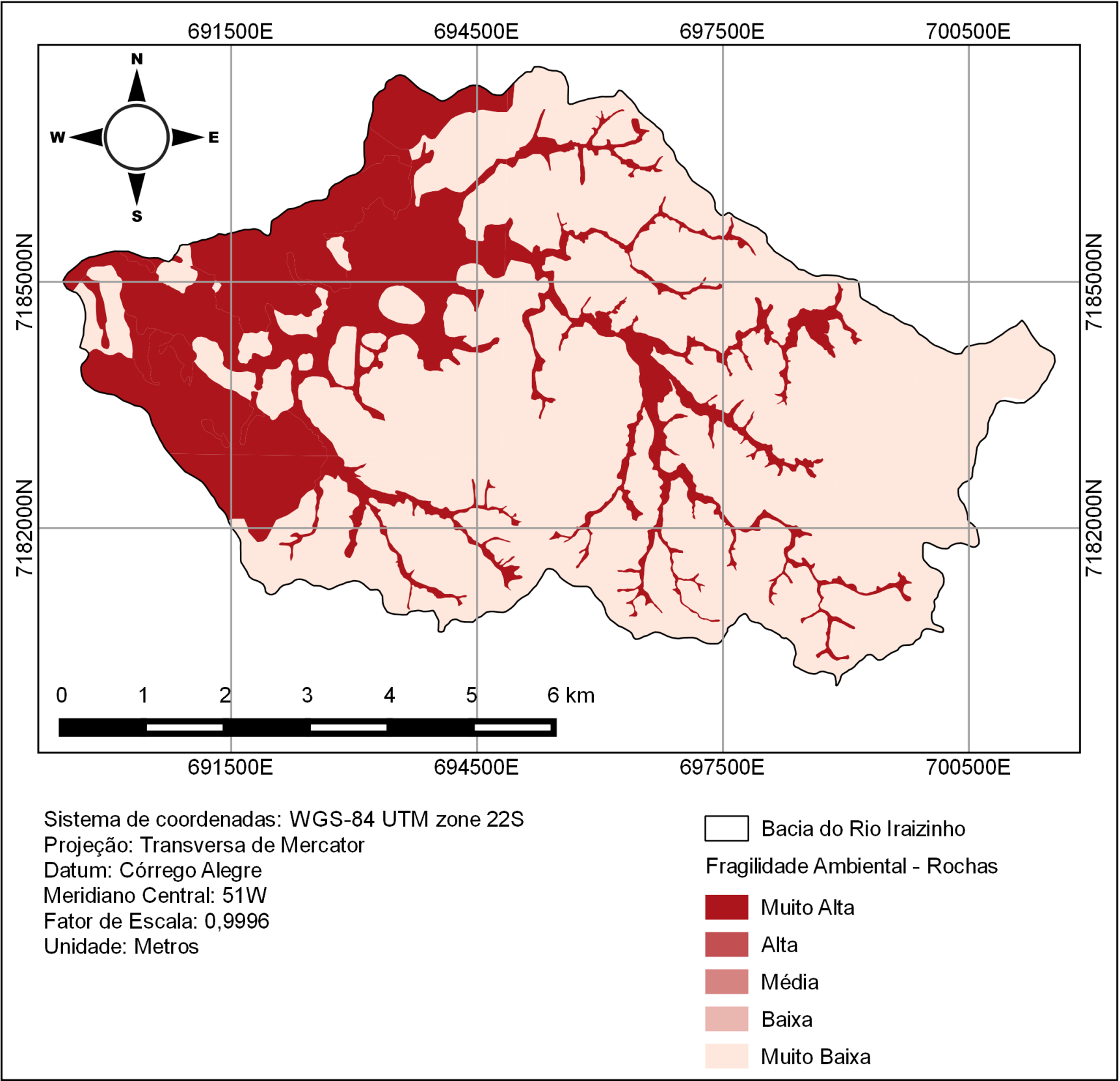

\section{5 Índice parcial de Fragilidade de Ação Antrópica}

A partir da elaboração do mapa de ação antrópica, podemos constatar que as atividades antrópicas são agravantes do processo, relacionando diretamente o aumento de erosão pluvial, por práticas agrícolas inadequadas e infraestrutura precária de urbanização, bem como pela modificação da velocidade dos cursos d'água por barramentos, desvios, entre outros causados pela ação do homem. Na Figura 7 podemos constatar que o maior índice de fragilidade encontrado se localiza na parte inferior do mapa, ou seja, na regiáo sul. 
Figura 7 - Mapa de Índice Parcial de Fragilidade Antrópico da Bacia Hidrográfica do Rio Iraizinho - PR

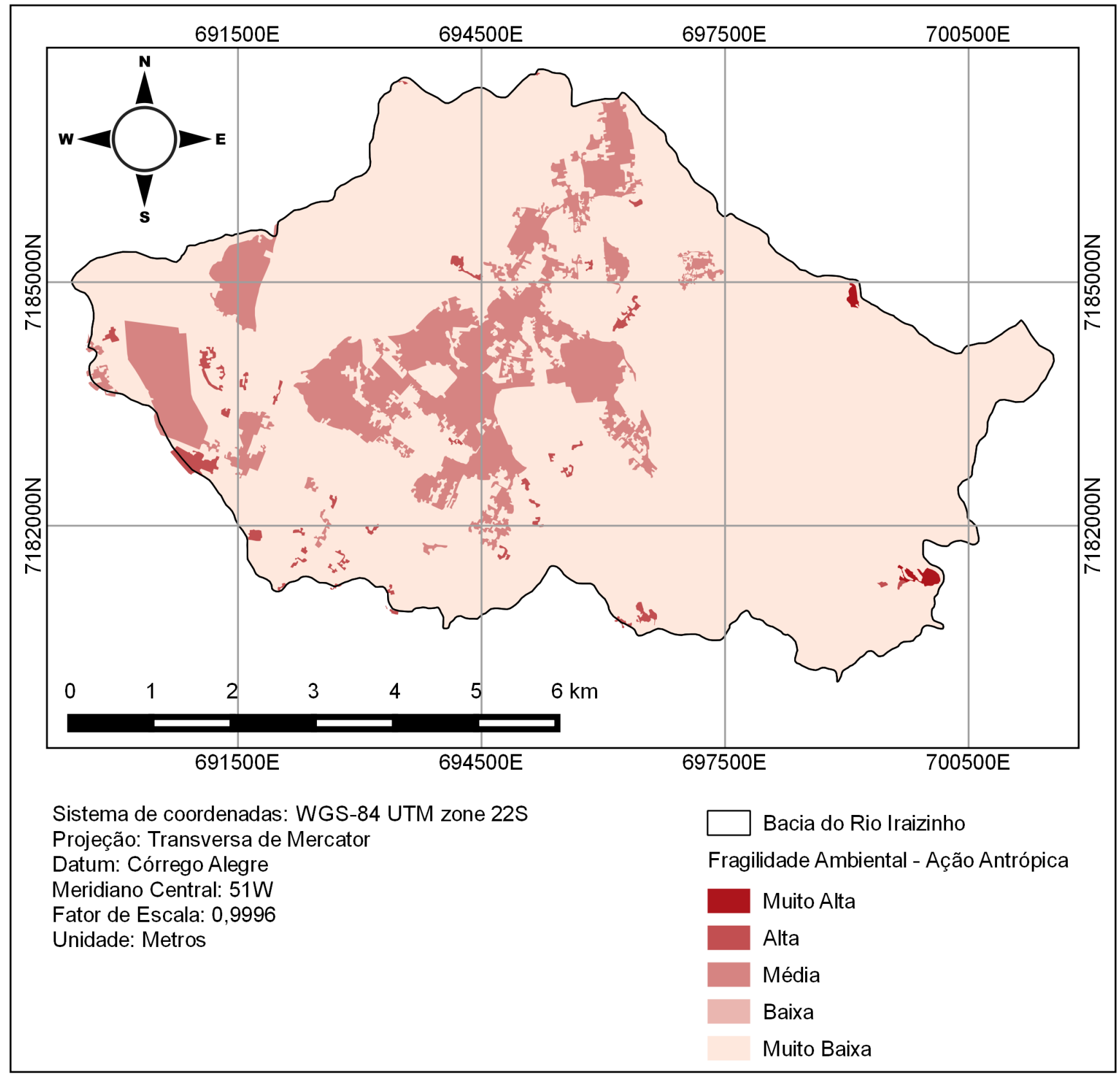

\section{6 Índice parcial de Fragilidade de Áreas de Preservação Permanente}

Em acordo com os critérios estabelecidos na legislação, as áreas protegidas foram mapeadas seguindo metodologia específica para cada uma das classes descritas no item 2.2.6 deste trabalho, que se caracteriza em preservar a vegetação do entorno dos rios e nascentes.

O mapa de fragilidade de áreas e preservação permanente, (Figura 8) constatou-se que as áreas com maior índice de fragilidade, encontram-se dentro do limite das áreas de preservaçáo permanente, sendo notadas em toda extensão da bacia. 
Figura 8 - Mapa de Índice Parcial de Fragilidade de APP da Bacia Hidrográfica do Rio Iraizinho - PR

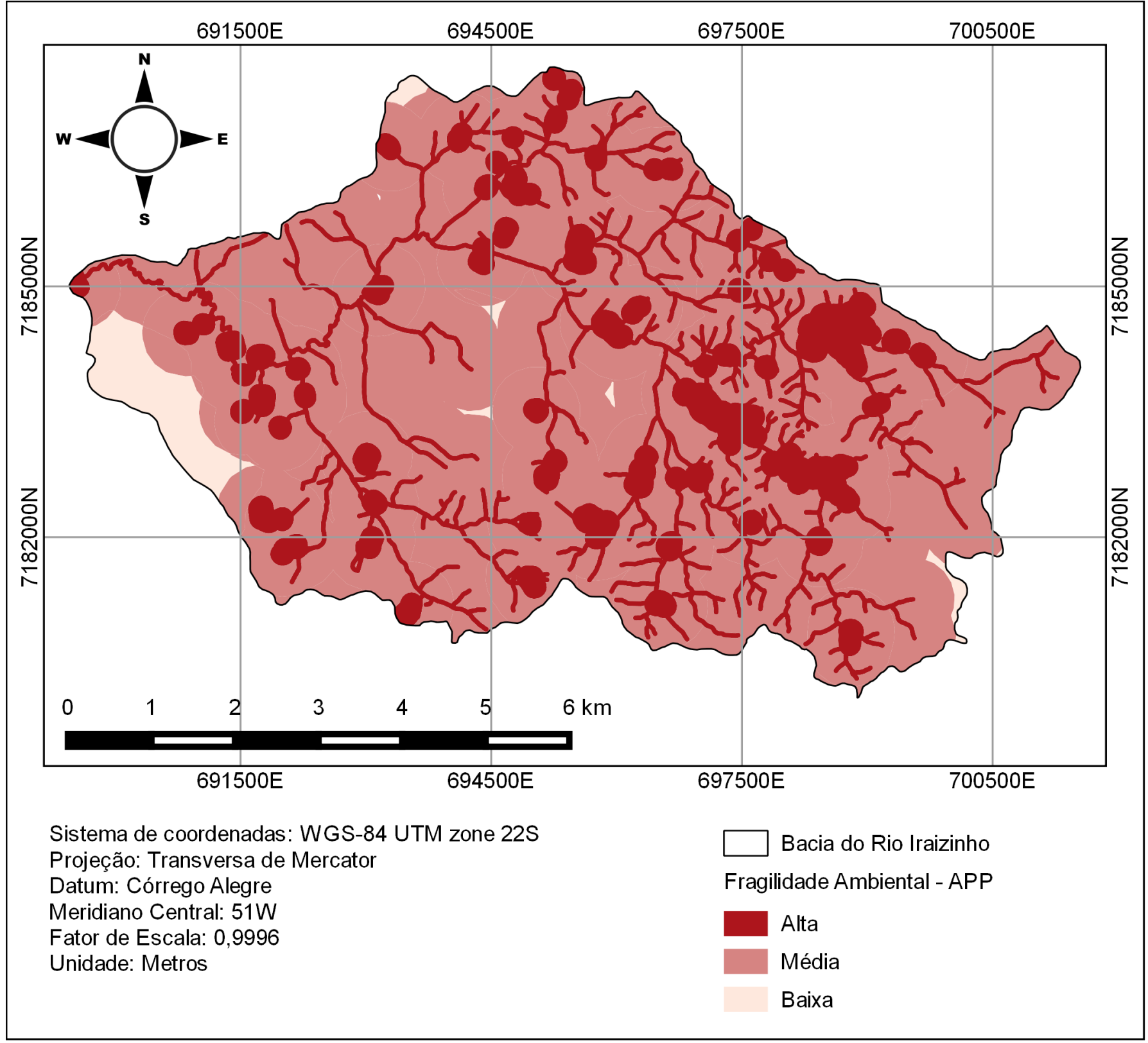

\section{7 Índice parcial de Fragilidade do Clima}

De forma geral, o clima do Município de Piraquara classifica-se como Clima subtropical úmido mesotérmico, de verōes frescos e com ocorrência de geadas severas e frequentes, não apresentando estação seca. A média das temperaturas dos meses mais quentes é inferior a $22^{\circ} \mathrm{C}$ e a dos meses mais frios é inferior a $18{ }^{\circ} \mathrm{C}$ (MAACK, 2002). Chove o ano todo, com precipitaçoes mensais superiores aos 60 $\mathrm{mm}$, mesmo nos meses mais secos. De maneira geral, a umidade aumenta com a proximidade da Serra do Mar (Silveira, 2005). Na Figura 9, mostra-se as alturas de precipitação totais anuais em milímetros da estação Mananciais da Serra localizada na Bacia do Rio Iraizinho, disponibilizadas pelo Secretaria do Meio Ambiente e Recursos Hídricos do Paraná. 
Figura 9 - Precipitação total anual entre 1986 e 2015

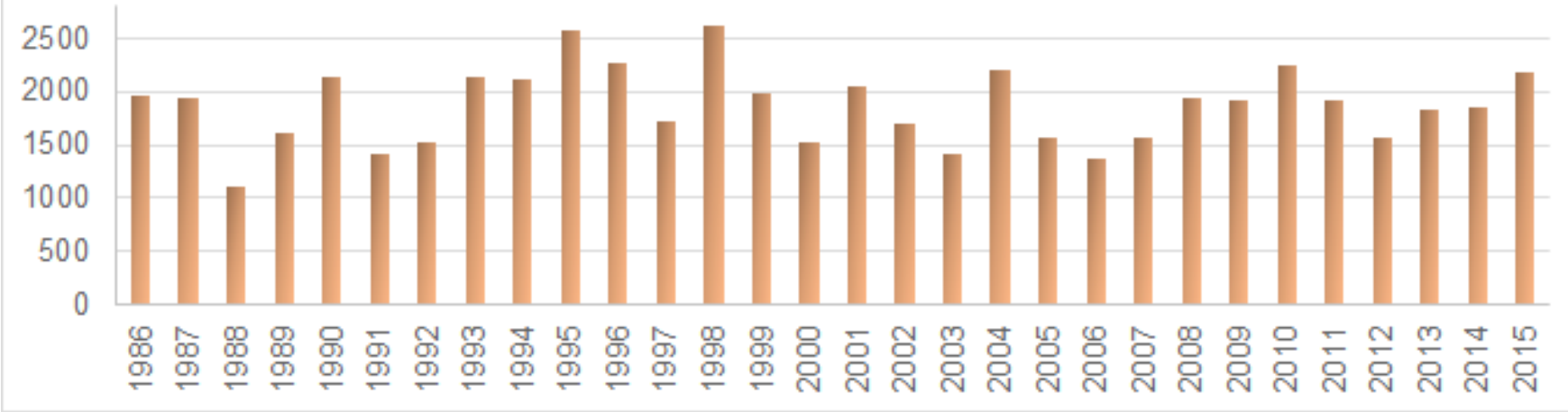

No mapa de fragilidade do clima (Figura 10), com um baixo índice de fragilidade em toda extensão podemos constatar que a área em estudo se apresentou da bacia.

Figura 10 - Mapa de Índice Parcial de Fragilidade de Clima da Bacia Hidrográfica do Rio Iraizinho - PR

(1)




\section{CONCLUSÕES}

A aplicação da metodologia IFA, demonstrou ser um recurso que permite adaptá-la conforme os interesses do pesquisador e as características da área de estudo. Porém, para a determinação de resultados mais significativos existe a necessidade da correlação espacial de todos os índices parciais demarcados.

Em relação ao uso e ocupação do solo, observouse que a área urbanizada aumentou em diferentes direções, causando preocupação com o destino dos mananciais, pois o uso dos recursos naturais superficiais e o lançamento de efluentes nos cursos d'água tem gerado cada vez mais a perda da qualidade da água, situaçáo já encontrada em grande parte dos rios que abastecem a Capital e sua Região Metropolitana.

Quanto à fragilidade potencial do meio natural, a bacia apresenta em sua maioria áreas de fragilidade baixa representando assim, regiôes pouco impactadas, pois ainda possui cobertura florestal contribuindo na proteção do solo.

Com relação a fragilidade emergente, a bacia hidrográfica do Rio Iraizinho, apresenta áreas de fragilidade emergente alta o que corresponde a futuros problemas ambientais se não for feito um planejamento da região de estudo, pois são áreas de campo e agricultura, ou seja, de intenso manuseio e ocupação, podendo assim, ocasionar alteraçóes ambientais como a contaminação dos mananciais para o abastecimento público. Para futuros estudos podemos indicar a elaboração de novas pesquisas que possibilitem auxiliar no planejamento da área, onde deverão ser estipuladas regiôes de melhor utilização para o uso e ocupação do solo, complementando-se com dados socioeconômicos aliados aos dados do meio físico, compatibilizando assim a proteção ambiental com o desenvolvimento econômico da bacia.

Por fim considera-se que é de suma importância obter informaçôes sobre os fatores que causam as mudanças no meio, pois esses podem auxiliar na tomada de decisóes na gestão e planejamento ambiental delimitando áreas que possam estar propensas a impactos positivos ou minimizar os impactos negativos. Como o meio pode sofrer alteraçôes, periodicamente as análises devem ser realizadas, para que os resultados obtidos forneçam informaçóes consistentes e confiáveis.

\section{Agradecimentos}

A SUDERHSA (Superintendência de Desenvolvimento de Recursos Hídricos e Saneamento Ambiental) e Instituto das Águas do Paraná pela disponibilização dos arquivos digitais referentes a dados espaciais que possibilitaram a geração de mapas e análises espaciais. Ao CNPq (Conselho Nacional de Desenvolvimento Científico e Tecnológico) pelo apoio financeiro através das bolsas concedidas aos estudantes de graduação.

\section{REFERÊNCIAS BIBLIOGRÁFICAS}

CHUEH, A. M. Análise do uso do solo e degradação ambiental na bacia hidrográfica do

rio Pequeno - São José dos Pinhais/PR, por meio do diagnóstico físico-conservacionista - DFC. Dissertaçáo (Mestrado em Geografia). Curitiba: Universidade Federal do Paraná, 2004. 102p.

COSTA, N. M. C. da; COSTA, V. C. da ; SANTOS, J. P. C. dos 2009 Definição e Caracterização de Áreas de Fragilidade Ambiental, com Base em Análise Multicritério, em Zona de Amortecimento de Unidades de Conservaçẫo. In: 120 Encuentro de Geógrafos de América Latina - EGAL 2009, 2009, Montevideo - Uruguai. Anais: 12 Encuentro de Geógrafos de América Latina - Caminando en una América Latina en transformación, 2009.

CREPANI, E.; MEDEIROS, JS; AZEVEDO, L.C.; DUARTE, V.; HERNANDEZ, P.; FLORENZANO, T.; BARBOSA, C. Sensoriamento Remoto e geoprocessamento aplicados ao zoneamento Ecológico-Econômico e ao ordenamento territorial. INPE, São José dos Campos, São Paulo, 2001.

DONHA, A.G. Avaliação do uso de técnicas de suporte a decisão na determinação da fragilidade em ambiente de geoprocessamento.. Dissertaçáo (Mestrado em Ciência do Solo). Curitiba: Universidade Federal do Paraná, 2003. 131p.

LEANDRO, D. Modelagem de fragilidade ambiental usando índices baseados em dados especiais e com suporte de sistema especialista. Tese (doutorado). Curitiba: Universidade Federal do Paraná, 2013. 120p.

MAACK, R. Geografia física do estado do Paraná. ed. 3. Curitiba: Imprensa Oficial, 2002. 440 p.

MESSIAS, C. G. (2012) Análise empírica de fragilidade ambiental utilizando técnicas de geoprocessamento: o caso da área de influencia da hidrelétrica do Funil $₫$ MG. Revista Geonorte, Edição Especial, V.2, N.4, p.112 - 125, 2012.

OLIVEIRA, P. C. A.; RODRIGUES, G. S. S. C.; RODRIGUES, S. C. Fragilidade ambiental e uso do solo da bacia hidrográfica do Córrego Pindaíba, Uberlândia, MG, Brasil. Revista AmbiÁgua. Taubaté, v.3, n. 1, p. 54-67, 2008.

PACHECHENIK, P. E. Caracterização hidrológica e da fragilidade ambiental na bacia do rio das Pedras, Guarapuava PR. Curitiba. Dissertaçáo (Mestrado em Ciência do

Solo), Universidade Federal do Paraná, 2004. 92p.

RESOLUÇÃO No 303, DE 20 DE MARÇO DE 2002. Disponível em <http://www.mma.gov.br/port/conama/res/ 
res02/res30302.html>. Acessada em: 2 de março de 2010. ROSS, J. L. S. Geomorfologia: Ambiente e planejamento. S. Paulo: Contexto, 1990.ROSS, J. L. S. Análise empírica da fragilidade dos ambientes naturais e antropizados. Revista do Departamento de Geografia. FFLCH-USP n. 9, p. 63-74, 1994. ROSS, J. L. S. Geomorfologia Aplicada aos Eias-Rimas. In: GUERRA, A.J.T; CUNHA, S.B. Geomorfologia e Meio Ambiente. Bertrand Brasil, 4a ed. Rio de Janeiro- RJ, 1996 p. 291-336.

SANTOS, R. F. dos. Planejamento ambiental: teoria e prática. São Paulo: Oficina de Textos, 2004.

SANTOS, I.; VITTE, A. C. Proposta de mapeamento da fragilidade ambiental da bacia hidrográfica do Rio Palmital, Regiáo Metropolitana de Curitiba. I Fórum Geo-Bio-
Hidrológico. Anais. Curitiba, 1998.

SILVEIRA, C. T. Estudo das Unidades Ecodinâmicas da Paisagem na APA de Guaratuba: subsídios para o planejamento ambiental. Curitiba. Dissertaçáo (Mestrado em Geologia). Curitiba: Universidade Federal do Paraná, 2005.

SPÖRL, C. Metodologia para elaboração de modelos de fragilidade ambiental utilizando redes neurais. Tese (Doutorado em Geografia Física). São Paulo: Faculdade de Filosofia, Letras e Ciências Humanas da Universidade de São Paulo, 2007.

SPÖRL, C.; ROSS, J. L. S. Análise comparativa da fragilidade ambiental com aplicaçáo de três modelos. Artigo. GEOUSP Espaço e Tempo, n. 15, p. 39-49, 2004.

TRICART, J. Ecodinâmica. FIBGE: Rio de Janeiro, 1977. 